Article

\title{
Potential of Room Acoustic Solver with Plane-Wave Enriched Finite Element Method
}

\author{
Takeshi Okuzono $^{1, * \mathbb{D}}$, M Shadi Mohamed ${ }^{2} \mathbb{D}$ and Kimihiro Sakagami ${ }^{1}$ (D) \\ 1 Environmental Acoustics Laboratory, Department of Architecture, Graduate School of Engineering, \\ Kobe University, Kobe 657-8501, Japan; saka@kobe-u.ac.jp \\ 2 School of Energy, Geoscience, Infrastructure and Society, Heriot-Watt University, Edinburgh EH14 4AS, UK; \\ M.S.Mohamed@hw.ac.uk \\ * Correspondence: okuzono@port.kobe-u.ac.jp; Tel.: +81-78-803-6577
}

Received: 27 February 2020; Accepted: 11 March 2020; Published: 13 March 2020

check for updates

\begin{abstract}
Predicting room acoustics using wave-based numerical methods has attracted great attention in recent years. Nevertheless, wave-based predictions are generally computationally expensive for room acoustics simulations because of the large dimensions of architectural spaces, the wide audible frequency ranges, the complex boundary conditions, and inherent error properties of numerical methods. Therefore, development of an efficient wave-based room acoustic solver with smaller computational resources is extremely important for practical applications. This paper describes a preliminary study aimed at that development. We discuss the potential of the Partition of Unity Finite Element Method (PUFEM) as a room acoustic solver through the examination with 2D real-scale room acoustic problems. Low-order finite elements enriched by plane waves propagating in various directions are used herein. We examine the PUFEM performance against a standard FEM via two-room acoustic problems in a single room and a coupled room, respectively, including frequency-dependent complex impedance boundaries of Helmholtz resonator type sound absorbers and porous sound absorbers. Results demonstrated that the PUFEM can predict wideband frequency responses accurately under a single coarse mesh with much fewer degrees of freedom than the standard FEM. The reduction reaches $\mathcal{O}\left(10^{-2}\right)$ at least, suggesting great potential of PUFEM for use as an efficient room acoustic solver.
\end{abstract}

Keywords: frequency domain; PUFEM; room acoustics; wave-based method

\section{Introduction}

\subsection{Background}

Acoustic simulation methods are necessary tools for predicting impulse responses or frequency responses of room spaces in architectural acoustics design. These quantities are necessary to evaluate room acoustics with acoustical parameters such as reverberation times, and the clarity of speech or music. These can also be used for the visualization and auralization of sound fields. Wave-based numerical methods, which solve a wave equation or a Helmholtz equation numerically, are physically reliable simulation methods with the capability of capturing wave phenomena such as interference and diffraction, and also of modeling boundary effects accurately by sound diffusers and sound absorbers. The finite element method (FEM) [1-5], boundary element method (BEM) [6], and finite difference time domain (FDTD) [7-9] method exemplify the often-used numerical methods for room acoustic simulations. Although they entail a huge computational effort for acoustic simulations especially at kilohertz frequencies in a real-sized room, their application to room acoustics prediction is increasing gradually by virtue of the progress of computer technology and the continuous development of efficient 
methods [9-24]. In addition, some recent studies [16,18,22,25] use extended-reaction boundary conditions to address both the frequency dependent and incident-angle dependent absorption characteristics of sound absorbers accurately, whereas many studies use the simplest local-reaction boundary conditions, which simplify the incident-angle dependence of surface impedance. Nevertheless, wave-based predictions are still time-consuming. Therefore, the development of more efficient methods or optimizing the performance has a marked impact in room acoustics field. This report presents a preliminary study to this end particularly using FEM in the frequency domain solving the Helmholtz equation with a few degrees of freedom (DOF).

The huge computational effort necessary for performing reliable acoustic simulations in real-sized rooms using FEM stems from the large dimension of spaces, the broad frequency range of interest, the complicated boundary conditions, and an inherent error property of FEM. The volumes of architectural spaces such as offices, lecture rooms, and concert halls range from the order of $10 \mathrm{~m}^{3}$ to $10,000 \mathrm{~m}^{3}$. The human audible frequency is $20 \mathrm{~Hz}$ to $20 \mathrm{kHz}$. In addition, the sound-absorption characteristics of boundary materials, which depend on both frequency and incident-angle of sound, should be modeled accurately. However, FEM is well known to have inherent spatial discretization error called dispersion error, which is an error evaluated in sound speed or in wavelength. To maintain the error within an acceptable level, the discretization of spaces, i.e., mesh generation, must be performed with consideration of a rule of thumb, e.g., for linear elements spatial discretization of 10 elements per wavelength at least. This discretization rule imposes the use of a large FE models with many DOF for acoustic simulation of a real-sized room, making the solution of the problem prohibitively expensive. For instance, in earlier works [4,5] conducted with high-order finite elements [26], the acoustics in a multi-purpose hall of $37,000 \mathrm{~m}^{3}$ were simulated using an FEM model of 2,630,435 DOF at $125 \mathrm{~Hz}$. The acoustics in a small hall with complicated diffusers were analyzed using an FEM mesh with 8,926,001 DOF. A recent study [27] conducting simulations at kilohertz frequencies used FEM models with the order of ten million DOF for both acoustic simulations of a simply shaped concert hall and the reverberation absorption coefficient measurement though the use of a dispersion-reduced scheme [28]. Furthermore, when using extended-reaction boundary conditions, the required elements increase because of the discretization of materials. Therefore, the development of room acoustic FEM solvers able to perform reliable simulations with an FE model having much fewer DOF is one direction for enhancing the applicability of FEM to room acoustic problems.

\subsection{Partition of Unity Finite Element Method for Acoustic Problems}

As a numerical method with such potential, acoustic numerical methods based on the Partition of Unity FEM [29] (PUFEM) have been formulated and examined in some studies [30-40]. Two papers [36,37] present demonstrations of PUFEM on 2D car interior analyses at high frequencies including porous absorbing materials modeled respectively using an equivalent fluid model [41-44] and poroelastic material model [45]. A very recent study [35] examined a 2D plane wave-scattering problem by which PUFEM can significantly reduce the DOF of the FEM model at high frequencies. The study also includes demonstration of partition of unity isogeometric analysis of 2D car interior sound field analysis at $20 \mathrm{kHz}$. The ability of acoustic PUFEM or PU-based method derives from enriching the approximation of sound fields by incorporating the general solution of Helmholtz equation into finite element approximation. For example, when using plane waves as the general solution, the sound pressure at a nodal point is expressed by the superposition of plane waves propagating various directions. It incorporates into local finite element approximation via the partition of the unity property. Additionally, sound fields are approximated up to high frequencies using $q$-refinement, which is a refinement technique by which plane waves propagating in various directions are added at nodal points of a fixed mesh gradually with increasing frequency. The most notable feature of acoustic PUFEM is that it obviates re-meshing according to frequencies, which is necessary for conventional FEM. Actually, PUFEM analysis can use elements of many times greater length than the wavelength of analyzed frequency, whereas conventional linear FEM must use an element 
size satisfying less than one-tenth of the wavelength of the analyzed frequency, as described above. Some closely related approaches with PUFEM exist. A review article presents additional details [46].

The PUFEM feature is apparently favorable for room acoustic simulations. In addition, the plane wave enrichment is applicable to any FEM mesh. That characteristic is useful to improve the existing FEM code performance. However, acoustic PUFEM is still developing. Various aspects remain to be studied for application to practical room acoustic simulations. In most earlier works [35-37], the potential of PUFEM for practical applications has been presented on 2D acoustic analysis in a small car having an area of less than $3 \mathrm{~m}^{2}$, without quantitative comparison with reference solutions. Additionally, those studies examine only pure tone analyses at high frequencies. Therefore, from the perspective of room acoustic applications, it remains unclear how PUFEM will perform robustly and accurately for problems of calculating wideband frequency responses in larger interior sound fields such as architectural spaces. This is an extremely important aspect because room acoustic simulations specifically address large room models and require wideband frequency components with fine frequency resolution especially for calculating room impulse responses. For reference, such an evaluation using frequency-domain methods can be found in earlier reports of the literature $[16,23,24]$. This study is the first attempt at revealing the PUFEM performance for wideband frequency response analysis in room acoustic problems with quantitative evaluation in accuracy. The architectural spaces treated here have 13-20 times larger dimensions than earlier studies.

\subsection{Purpose of This Study}

This study was conducted to discuss the potential of the plane-wave-enriched FEM as a room acoustic solver via performance examination on $2 \mathrm{D}$ real-scale room acoustic problems through numerical experiments. This is a preliminary study toward constructing an efficient 3D room acoustic solver. Plane-wave-enriching low-order FEs are used herein to discretize spaces. Local-reaction impedance boundary modeling is used to address the absorption characteristics of sound absorbers such as Helmholtz resonators and porous absorbers. As the main result, we can report whether or not PUFEM can predict wideband frequency responses robustly and accurately from low frequencies to high frequencies with a fine frequency resolution and with a single coarse mesh having a small amount of DOF. Our study also includes a performance comparison against conventional linear FEM having second-order accuracy with respect to dispersion errors. The performance is measured in terms of both the prediction accuracy of sound pressure level, and in terms of the reduction effect of DOF. We use two problems including realistic boundary impedance of sound absorbers commonly used in the room acoustics field. Because the two problems have no analytical solutions, reference solutions are calculated using a fourth-order accurate FEM with fine meshes. The remainder of this study is organized as follows. For reader convenience, PUFEM approximation is briefly introduced in Section 2 where also important aspects related to choosing the numerical parameters are discussed. Section 3 presents examination of the applicability of PUFEM via both the sound field analysis in a single room and a more complex coupled room composed of four rooms. Section 4 concludes this study.

\section{Brief Preliminaries for Room Acoustic Simulations Using PUFEM}

\subsection{Interior Sound Field Analysis}

We consider a sound propagation problem in an interior sound field $\Omega$ with boundary $\Gamma$ composed of three boundary conditions: a rigid boundary $\Gamma_{0}$, a vibration boundary $\Gamma_{\mathrm{V}}$, and an impedance boundary $\Gamma_{Z}$, as shown in Figure 1. This problem is described in terms of the sound pressure $p$ using the following Helmholtz equation as

$$
\nabla^{2} p+k^{2} p=0, \quad \text { in } \Omega
$$

where $k$ represents the wavenumber. The three boundary conditions are given as 


$$
\frac{\partial p}{\partial n}=\left\{\begin{array}{cc}
0 & \text { on } \Gamma_{0} \\
-j \omega \rho_{0} v & \text { on } \Gamma_{\mathrm{v}} \\
-j k \frac{1}{z_{\mathrm{n}}} p & \text { on } \Gamma_{\mathrm{z}}
\end{array}\right.
$$

where $\omega$ represents the angular frequency, $\rho_{0}$ expresses the air density, $v$ signifies the vibration velocity, $z_{\mathrm{n}}$ stands for the normalized impedance ratio, and $-j$ denotes the imaginary unit $\left(j^{2}=-1\right)$. With the arbitrary weight function $\phi$, the weak form of Helmholtz equation for finite element discretization is given as

$$
\int_{\Omega}\left(-\nabla \phi \nabla p+k^{2} \phi p\right) d \Omega+\int_{\Gamma} \phi \frac{\partial p}{\partial n} d \Gamma=0
$$

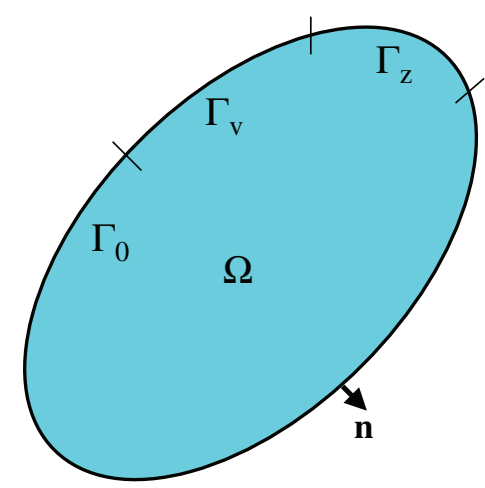

Figure 1. Interior sound field $\Omega$ where $\Gamma_{0}, \Gamma_{\mathrm{V}}$ and $\Gamma_{\mathrm{Z}}$ respectively represent a rigid boundary, a vibration boundary, and an impedance boundary. In addition, $\mathbf{n}$ is the outward normal.

\subsection{Plane-Wave Enriched Finite Elements in 2D Analysis}

In FEM, sound pressure at an arbitrary point $(x, y)$ within an element $\Omega_{\mathrm{e}}$ is approximated by product of shape functions $N_{i}(\xi, \eta)$ and nodal values of sound pressure $p_{i}$

$$
p(x, y)=\sum_{i=1}^{n} N_{i}(\xi, \eta) p_{i}
$$

where $\xi$ and $\eta$ are the local coordinate system. In plane-wave enriched finite elements, the plane wave, which is the general solution of Helmholtz equation, is incorporated into shape functions via the partition of unity property $[33,34]$. Nodal values of sound pressure $p_{i}$ are approximated with the superposition of plane waves propagating in various directions as

$$
p_{i}=\sum_{l=1}^{q} A_{i}^{l} e^{j k\left(x \cos \theta_{l}+y \sin \theta_{l}\right)},
$$

where $q$ stands for the number of plane waves, $\theta_{l}$ denotes the angles of plane waves in polar coordinate systems, and $A_{i}^{l}$ expresses the amplitude of plane wave propagating in a direction $\theta_{l}$. As presented in this report, $\theta_{l}$ are set as evenly distributed angles $\theta_{l}=2 \pi l / q$. Substituting Equation (5) into Equation (4) engenders a plane wave enriched approximation of sound pressure at an arbitrary point within an element as

$$
p(x, y)=\sum_{i=1}^{n} \sum_{l=1}^{q} N_{i}(\xi, \eta) e^{j k\left(x \cos \theta_{l}+y \sin \theta_{l}\right)} A_{i}^{l} .
$$


As presented in Equation (6), the plane wave enrichment is applicable to any finite element with a different shape function. By defining a new shape function $P$ as the product of the shape function and the plane wave with unit amplitude, Equation (6) can be expressed as shown below:

$$
p(x, y)=\sum_{i=1}^{n} \sum_{l=1}^{q} P_{(i-1) q+l} A_{i}^{l}
$$

The equation above is used for PUFEM discretization of the weak form of Equation (3).

\subsection{Semi-Discretized Matrix Equation}

We apply PUFEM discretization [33,34] with a Galerkin approach to the integral equation of Equation (3); then, consideration of the three boundary conditions in Equation (2) engenders the following semi-discretized matrix equation as

$$
\sum_{e}^{n_{e}}\left[\int_{\Omega_{\mathrm{e}}}\left(\nabla \boldsymbol{P}^{\mathrm{T}} \nabla \boldsymbol{P}-k^{2} \boldsymbol{P}^{\mathrm{T}} \boldsymbol{P}\right) d \Omega+j \frac{k}{z_{\mathrm{n}}} \int_{\Gamma_{\mathrm{e}, \mathrm{z}}} \boldsymbol{P}^{\mathrm{T}} \boldsymbol{P} d \Gamma\right] \boldsymbol{A}=\sum_{e}^{n_{e}}\left[-j \omega \rho_{0} v \int_{\Gamma_{\mathrm{e}, \mathrm{v}}} \boldsymbol{P}^{\mathrm{T}} d \Gamma\right]
$$

where $\boldsymbol{P}$ is the shape function vector having components of the new shape function $P, A$ is the nodal amplitude vector, and $n_{e}$ represents the number of plane-wave enriched elements. For illustration in this report, we use plane-wave-enriched linear quadrilateral elements for spatial discretization. A high-order Gauss-Legendre rule is used for evaluating the domain integral and the boundary integral. Finally, the complex sound pressure in the domain $\Omega$ can be computed via Equations (6) or (7) with the plane wave amplitude $A_{i}^{l}$ obtained as the solution of the linear system of equations presented above.

\subsection{Numerical Setup of PUFEM}

To perform the efficient PUFEM analysis, it is important to apply a proper setup in some numerical parameters. First, it is necessary to use a proper number of Gauss points $n_{g}$ in the evaluations of domain integral and boundary integral according to the frequency to be analyzed. However, an established rule that can perform well in wide frequency ranges from low to high frequency remains insufficient. For this study, we applied the following rule obtained from a preliminary numerical experiment on plane wave propagation problem in a duct:

$$
n_{g}=\left\{\begin{array}{cc}
\operatorname{int}\left(10 n_{w}+1\right) & \left(n_{w} \geq 1\right) \\
10 & \text { otherwise }
\end{array}\right.
$$

Here, $n_{w}$ represents the maximum element length $h_{\max }$ relative to wavelength $\lambda$ defined as $n_{w}=h_{\max } / \lambda$, which represents the number of the wavelength included in each element. For high-frequency analyses, the well-used rule exists: around ten integration points per wavelength contained within each element. We applied the rule to frequencies $n_{w} \geq 1$ as in Equation (9). That is, we defined the frequencies satisfying $n_{w} \geq 1$ as high frequencies. Other recent proposed integration rules [39] may become a better alternative. However, the analytical integration scheme is limited to elements with straight edges and would be difficult to implement if the edges are curved. Since we are interested in real-world applications, we decided to use the numerical integration scheme as it is a more general approach and can be applied without alteration to any type or shape of elements. Furthermore, a proper setup for a way of adding how many plane waves at each nodal point along with frequency is important, but it remains insufficient as an established setup for wideband frequency analysis from low frequencies to high frequencies. We applied the following equation referred from earlier work reported in the literature [36]: 


$$
q=\operatorname{round}\left[k h_{\max }+C\left(k h_{\max }\right)^{\frac{1}{3}}\right],
$$

In Equation (10), $h_{\max }$ is the maximum element length in all elements. The constant $C$ adjusts the resulting accuracy. However, no way exists to set an appropriate value of $C$ in advance. An alternative mode of Equation (10) has been proposed for high frequencies. It has a discretization level of around 2.5 degrees of freedom per wavelength. This paper selected the use of Equation (10).

\section{Numerical Experiments}

We examine the PUFEM performance using plane-wave enriched quadrilateral elements through two numerical examples on the calculation of sound fields in a single room and in a coupled room, respectively, including local reaction impedance boundaries of a resonant absorber and a porous absorber. The two room models were created from reference to an existing office plan of the authors in Kobe University. The accuracy of PUFEM is shown in comparison with the standard FEM using linear quadrilateral elements, which has second-order accuracy with respect to the dispersion error. In addition, the PUFEM efficiency is measured by the reduction effect of DOF for achieving the equivalent level of accuracy. In both rooms, sound fields generated by acoustic emission from a loudspeaker placing in the room were calculated at $20 \mathrm{~Hz}$ to $2.5 \mathrm{kHz}$ with a $1 \mathrm{~Hz}$ interval. Because the two numerical examples have no analytical solutions, we used reference solutions calculated using a fourth-order accurate FEM with a dispersion reduction technique called modified integration rules [47]. The performance of fourth-order accurate FEM for 3D room acoustic simulations was described in earlier reports of the literature $[16,18,28,48]$. For this paper, a $2 \mathrm{D}$ version is used in the frequency domain [49]. The speed of sound and the air density were set, respectively, as $340 \mathrm{~m} / \mathrm{s}$ and $1.205 \mathrm{~kg} / \mathrm{m}^{3}$.

\subsection{Measurement of Accuracy}

The accuracy of numerical solutions was evaluated in terms of frequency responses of the sound pressure level (SPL). We define the following RMS error $L_{\mathrm{rms}}(f)$ with respect to the spatial distribution of SPL as

$$
L_{\mathrm{rms}}(f)=\sqrt{\frac{1}{N_{\text {point }}} \sum_{i=1}^{N_{\text {point }}}\left[L_{\mathrm{fem}}(f, i)-L_{\mathrm{ref}}(f, i)\right]^{2}},
$$

where $N_{\text {point }}$ signifies the number of receivers, $L_{\mathrm{fem}}(f, i)$ stands for the SPLs in a receiver $i$ at frequency $f$ calculated using the PUFEM and standard FEM, and $L_{\text {ref }}(f, i)$ denotes the SPL calculated using the reference solution. Furthermore, we performed $1 / 3$ octave band averaging to the RMS error to capture the error behavior easily:

$$
\bar{L}_{\mathrm{rms}}\left(f_{\mathrm{c}}\right)=\frac{1}{N_{\mathrm{f}}} \sum_{f=f_{\mathrm{l}}}^{f_{\mathrm{u}}} L_{\mathrm{rms}}(f) .
$$

Therein, $\bar{L}_{\text {rms }}\left(f_{\mathrm{c}}\right)$ represents the RMS error at $1 / 3$ octave band center frequency $f_{\mathrm{c}}, N_{\mathrm{f}}$ denotes the number of frequencies included within $1 / 3$ octave band, and $f_{1}, f_{\mathrm{u}}$ respectively denote the lower and upper limit frequencies.

\subsection{Sound Propagation in a Single Room}

\subsubsection{Problem Description and Numerical Setup}

Figure 2 portrays a single room with area $S_{\mathrm{a}}$ of $39.92 \mathrm{~m}^{2}$, including a small rectangular area $S$ assuming a loudspeaker where $\Gamma_{\mathrm{V}}$ is treated as the vibration boundary. The room's boundaries comprise a weakly absorbing impedance boundary $\Gamma_{z, 1}$ and an impedance boundary $\Gamma_{z, m}$ of honeycomb-backed 
microperforated panel (MPP) absorber with Helmholtz resonator type sound-absorption characteristics. The weakly absorbing surface $\Gamma_{z, 1}$ has real valued impedance corresponding to normal incidence sound absorption coefficient $\alpha_{0}=0.05$. For the MPP sound absorber, the sound absorption characteristics are frequency dependent in both $\alpha_{0}$ and $z_{n}$, as shown in Figure 2. A theoretical impedance model $[24,50]$ considering a limp MPP was used to calculate the $z_{\mathrm{n}}$. The geometrical parameters of MPP are $0.5 \mathrm{~mm}$ in hole diameter, $1 \mathrm{~mm}$ in plate thickness, $0.75 \%$ in perforation ratio, and $1.13 \mathrm{~kg} / \mathrm{m}^{2}$ in surface density. The backing honeycomb core thickness is $0.015 \mathrm{~m}$. With those specifications, the MPP absorber shows peak sound absorption at around $1 \mathrm{kHz}$. We applied $v=1 \mathrm{~m} / \mathrm{s}$ for the vibrating surface, assuming a speaker cone.
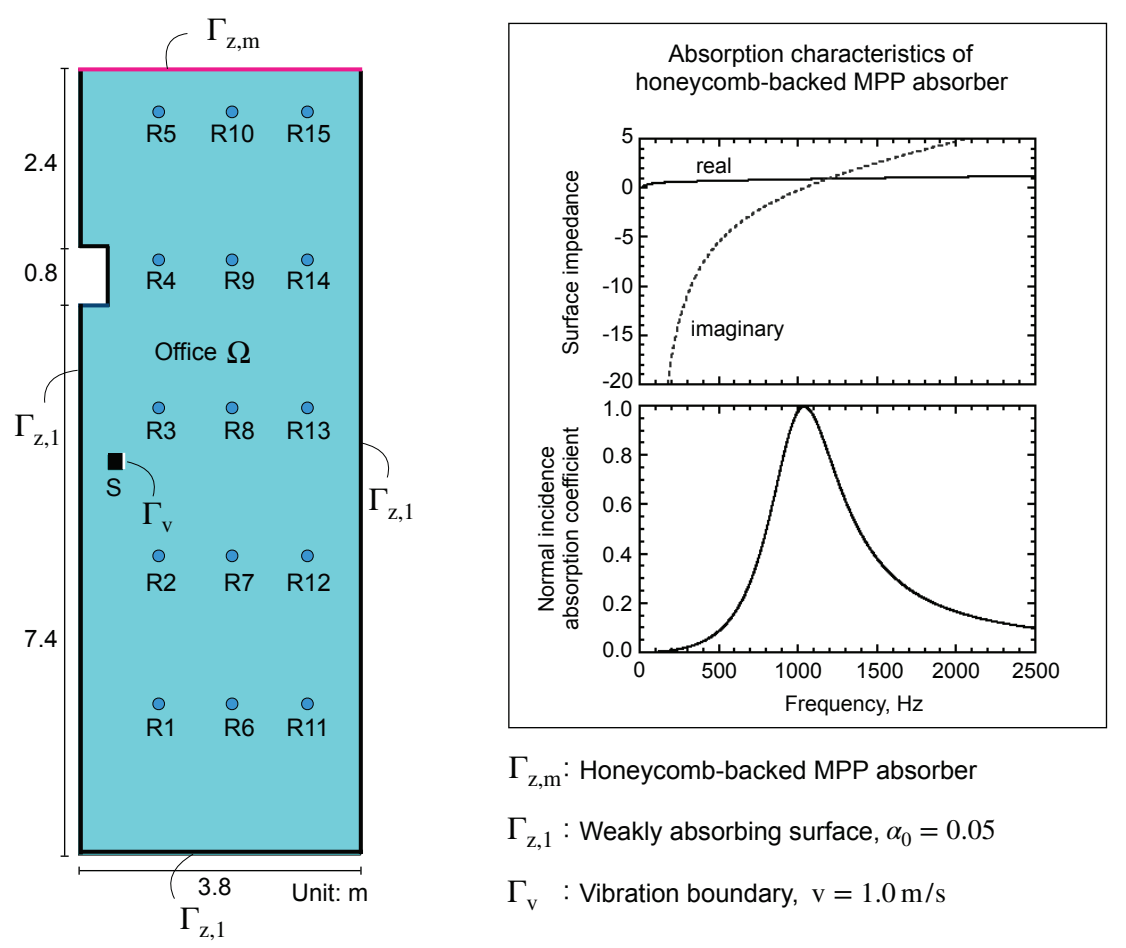

Figure 2. Single-room model including a vibration boundary, and impedance boundaries of weakly absorbing surfaces and honeycomb-backed microperforated panel absorbers: $\mathrm{S}$ and $\mathrm{R}$ respectively represent sound source and receivers.

Figure 3a,b show two PUFEM meshes, Mesh 1 and Mesh 2, with different spatial resolutions. Both meshes consist of elements larger than the wavelength of upper-limit frequency. Mesh 1 is a uniform mesh discretized with square elements of $0.2 \mathrm{~m}$ having 1.47 times larger size than the wavelength at $2.5 \mathrm{kHz}$. Mesh 2 is a non-uniform mesh discretized by rectangular elements of $0.2-0.4 \mathrm{~m}$ having 2.97 times larger size at maximum. The total numbers of elements $N_{\text {ele }}$ and nodes $N_{\text {node }}$ are 922 and 994, respectively, for Mesh 1. They are 267 and 307, respectively, for Mesh 2. The constant $C$ in Equation (10) was set as 5-14 with one interval. For the reference solution, two fine meshes with different spatial resolution were used for different frequency ranges. We used a mesh discretized with $0.01 \mathrm{~m}$ square elements with 400,720 DOF for analyses up to $1.5 \mathrm{kHz}$. Its spatial resolution is 22 elements per wavelength at $1.5 \mathrm{kHz}$. At higher frequencies, we used a mesh with 1,599,840 DOF discretized by $0.005 \mathrm{~m}$ square elements. Its spatial resolution is 27 elements per wavelength. Standard FEM analysis used the same meshes as those used for a reference solution. 


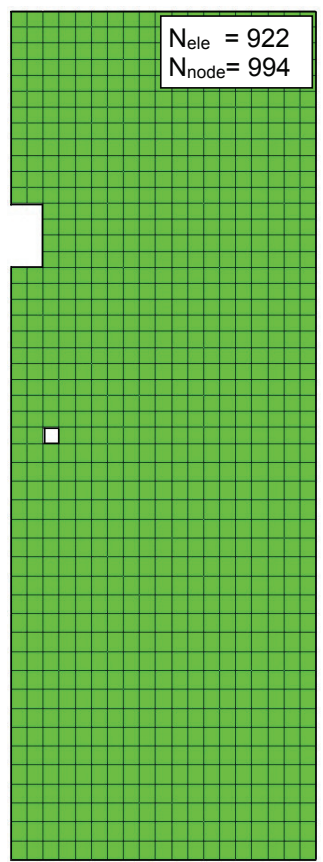

(a) Mesh1

$0.012 \leq n_{w} \leq 1.47$

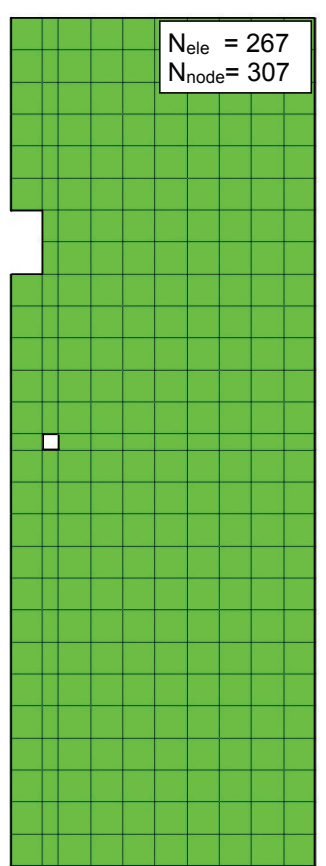

(b) Mesh2

$0.024 \leq n_{w} \leq 2.94$

Figure 3. PUFEM mesh with two spatial resolutions: (a) Mesh 1 and (b) Mesh 2. The range of $n_{w}$ is also shown for reference.

\subsubsection{Results and Discussion}

As an example of comparison of frequency responses, Figure $4 \mathrm{a}, \mathrm{b}$ respectively show comparisons of frequency response calculated using PUFEM and standard FEM at R1 with reference solution (Ref): (a) Ref versus PUFEM ( $C=13$, Mesh2), and (b) Ref versus standard FEM (0.01 m mesh). This figure visually presents the effectiveness of PUFEM. The standard FEM using $0.01 \mathrm{~m}$ mesh with 400,720 DOF shows a marked difference from the reference solution at higher frequencies than $1 \mathrm{kHz}$ because of the inherent large dispersion error, i.e., sound speed increases at higher frequencies, and the error magnitude becomes higher for larger domains. The PUFEM result shows much better agreement with the reference solution at entire frequencies despite the use of coarse mesh with 267 elements. Regarding the PUFEM analysis, Figure 5a,b show changes in the DOF for the entire frequency range when using Mesh 2 with $C=13$. The DOF in PUFEM is defined as the product of plane wave numbers $q$ for enrichment and nodes $N_{\text {node }}$ i.e., $\mathrm{DOF}=q \times N_{\text {node }}$. The DOF of PUFEM analysis changes from 2149 to 16,271 at frequencies of $20 \mathrm{~Hz}$ to $2.5 \mathrm{kHz}$, with a change in the plane wave numbers of 7-53. The PUFEM analysis has only 16,271 DOF at $2.5 \mathrm{kHz}$, which is $1 / 25$ smaller than the DOF of standard FEM.

Figure $6 \mathrm{a}, \mathrm{b}$ show RMS errors of both the standard FEM (0.01 m mesh) and the PUFEM with different values of $C$ for Mesh 1 and Mesh 2. We only present results with $C=5,7,9,11$, and 13 for ease of illustration of the error behavior. In the PUFEM results, the RMS errors are reduced overall with larger $C$. The larger value of $C$ is necessary to reduce the error at higher frequencies. This is true for Mesh 1 and Mesh 2. In comparison with standard FEM results, the PUFEM with $C \geq 6$ offers more accurate results at frequencies higher than $315 \mathrm{~Hz}$ in both Mesh 1 and Mesh 2. It is a very interesting capability of plane wave enrichment because the standard FEM with non-enriched elements uses very fine mesh at $315 \mathrm{~Hz}$, where the spatial resolution is 108 elements per wavelength. Regarding the RMS error at frequencies below $315 \mathrm{~Hz}$, PUFEM shows error of less than $1 \mathrm{~dB}$ when using $C \geq 7$ for Mesh1 and $C \geq 6$ for Mesh 2. It is an acceptable error magnitude for practical applications. Furthermore, standard FEM shows RMS error of $8.1 \mathrm{~dB}$ at $2 \mathrm{kHz}$ although the used mesh has 400,720 DOF. By contrast, PUFEM shows a significantly low error value of $0.76 \mathrm{~dB}$ in both Mesh 1 and Mesh 2 when using $C=13$. Additionally, we performed the standard FEM analysis with 
$0.005 \mathrm{~m}$ mesh having 1,599,840 DOF, which has spatial resolution of 34 elements per wavelength at $2 \mathrm{kHz}$. However, the result still shows an RMS error of $7.4 \mathrm{~dB}$ at $2 \mathrm{kHz}$ because, for large scale sound field analysis at high frequencies, the standard FEM results include large dispersion error as described previously. That result also demonstrates that the standard FEM requires a finer mesh to obtain the equivalent level of accuracy as the PUFEM results at $2 \mathrm{kHz}$. Based on those results, the PUFEM with Mesh 2 can probably perform more accurate analysis with at least 1/100 fewer DOF than the standard FEM does.
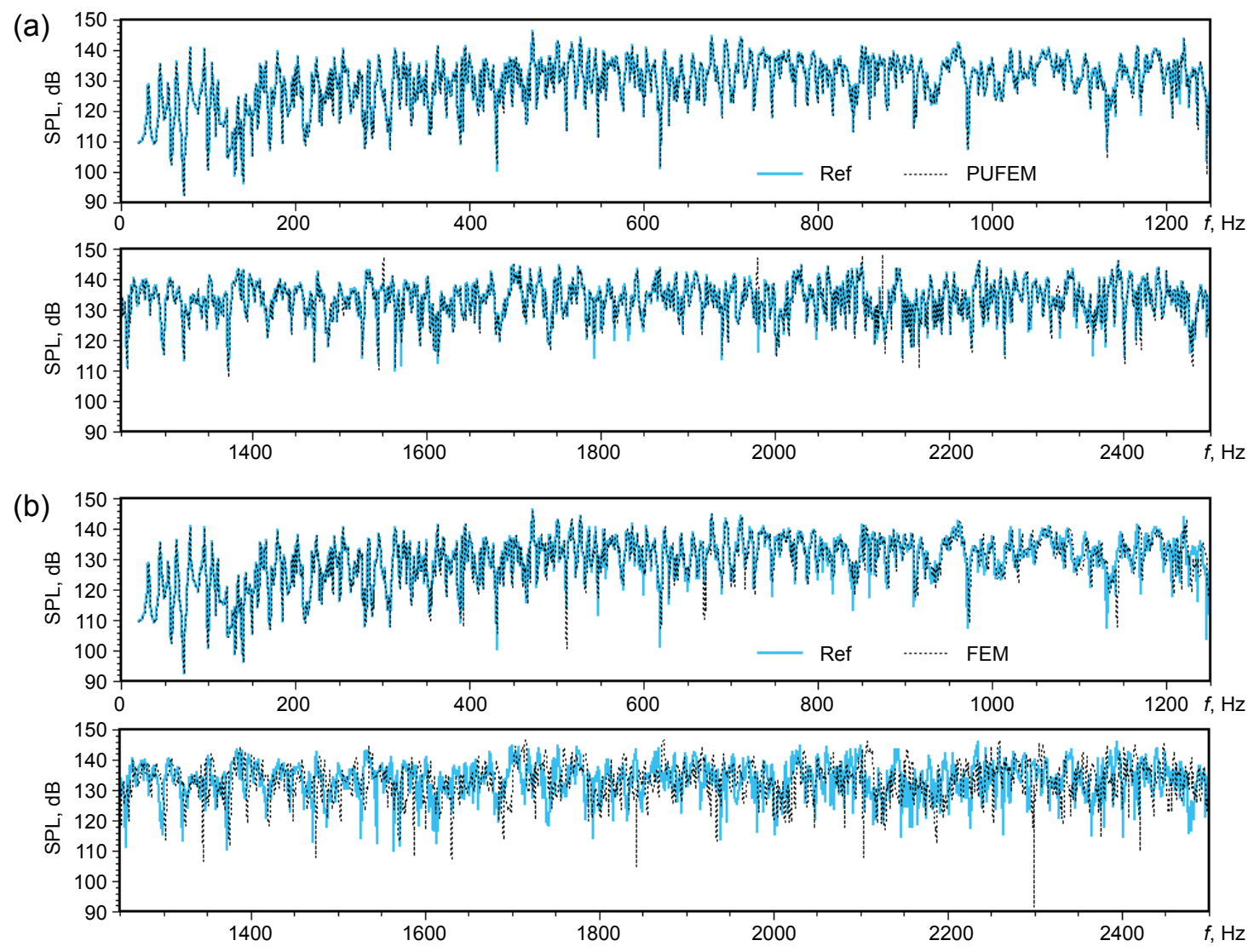

Figure 4. Comparison of frequency responses at R1: (a) reference solution (Ref) vs. PUFEM (C = 13, Mesh 2), and (b) reference solution vs. standard FEM (0.01 $\mathrm{m}$ mesh).
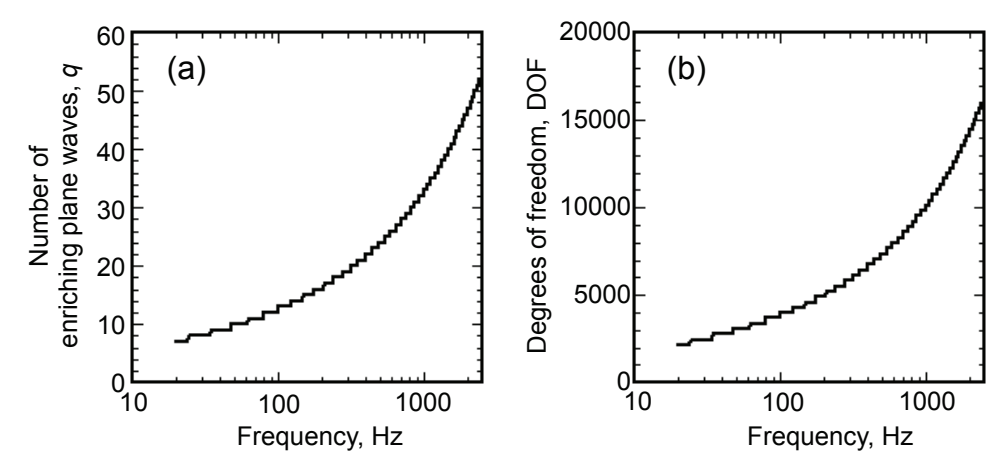

Figure 5. Changes in (a) the enriched plane waves number $q$ and (b) DOF when using Mesh 2 with $C=13$.

Furthermore, we present the convergence behavior of a solution against DOF and examine whether a coarse mesh or a fine mesh is effective. Figure 7a,d show relations between DOF and RMS error in PUFEM analysis using Mesh 1 and Mesh 2 at four higher frequency bands of $1 \mathrm{kHz}, 1.25 \mathrm{kHz}$, $1.6 \mathrm{kHz}$, and $2 \mathrm{kHz}$. They show that the coarse mesh, Mesh 2, achieves a practically acceptable error 
magnitude of less than $1 \mathrm{~dB}$ with fewer DOF than the finer mesh. This result suggests that the use of coarse mesh enriched by many plane waves is more effective than that of fine mesh enriched with a few plane waves from the aspect of computational cost. Additionally, we can observe an important aspect in the Mesh 2 results at $1 \mathrm{kHz}$ and $1.25 \mathrm{kHz}$. There exists a proper number of plane waves for enrichment, i.e., an increase of DOF does not always produce more accurate results. Similar results were obtained from an earlier study [33]. The earlier report described this as attributable to the ill-conditioning of the resulting linear system, showing an increase of the condition number when continuously increasing the attached plane wave numbers. In addition, the present paper showed the mesh size effect on the resulting accuracy in limited conditions. Therefore, comprehensive investigations on this topic will be shown in future works with well-organized numerical experiments.

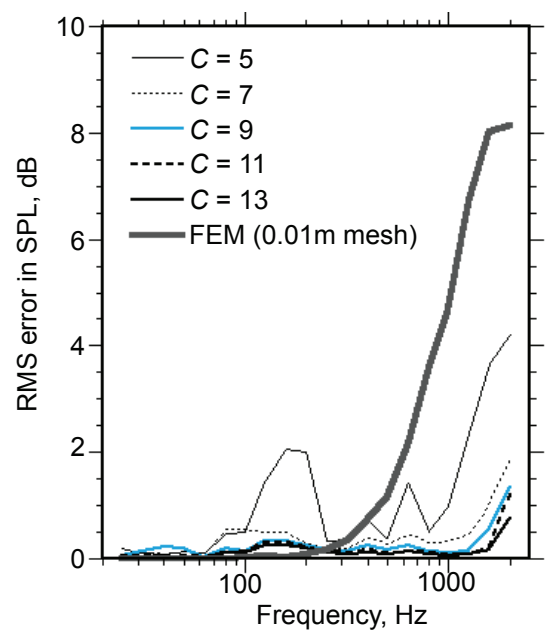

(a) Mesh1

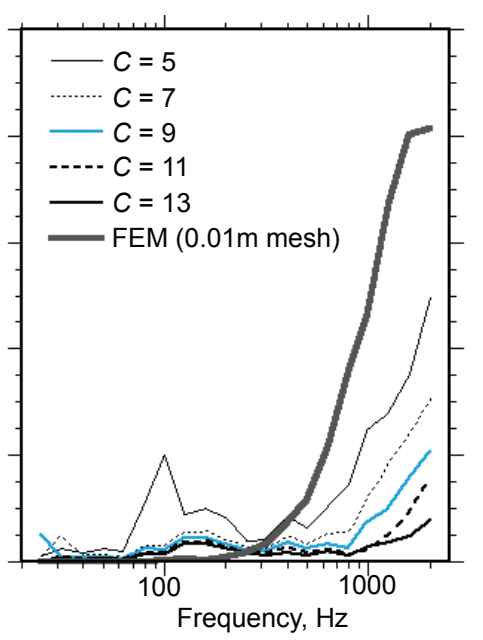

(b) Mesh2

Figure 6. Comparison of RMS error for (a) Mesh 1 and (b) Mesh 2. An FEM result obtained using $0.01 \mathrm{~m}$ mesh is also shown for comparison.
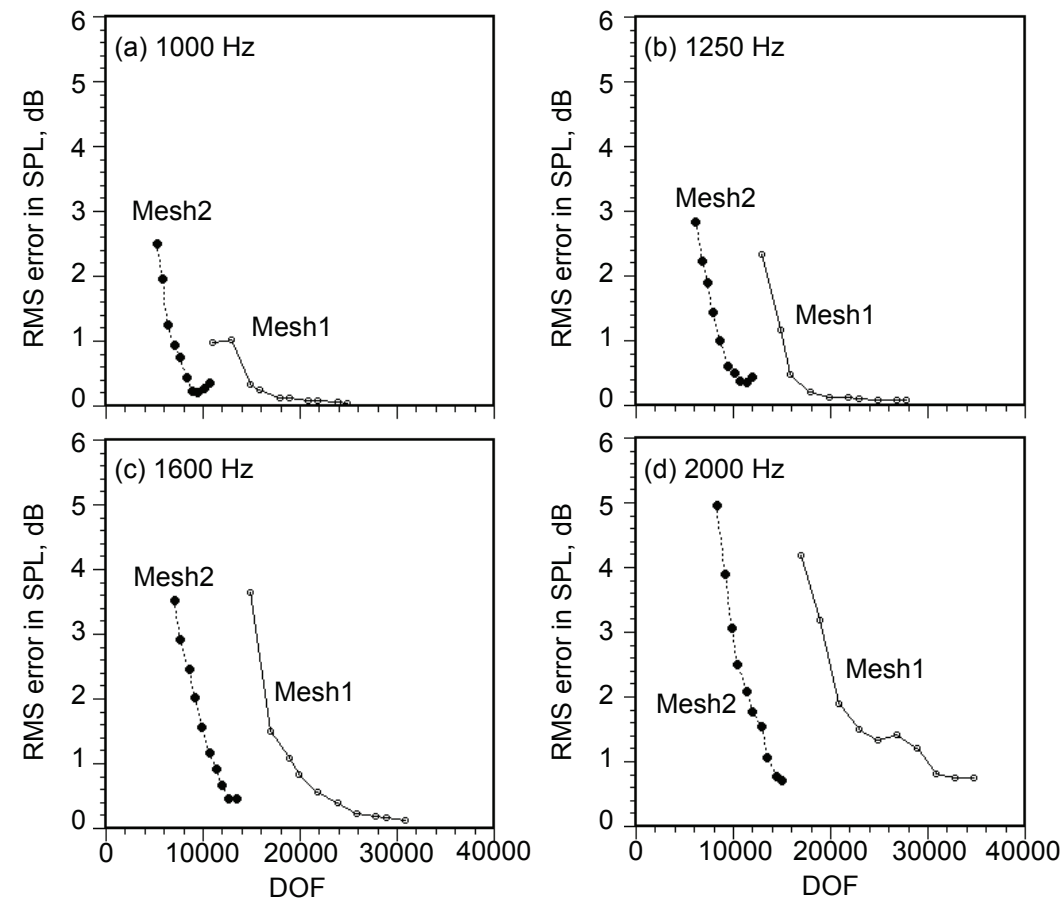

Figure 7. Relations between DOF and RMS error in PUFEM analysis at four higher frequency bands: (a) $1 \mathrm{kHz}$, (b) $1.25 \mathrm{kHz}$, (c) $1.6 \mathrm{kHz}$, and (d) $2 \mathrm{kHz}$. The DOF in the $x$-axis is the value at a center frequency within each band. 


\subsection{Sound Propagation Problem in a Coupled Room}

\subsubsection{Problem Description and Numerical Setup}

In the second example, a real-world acoustic application is considered again where the model is based on an existing office plan in Kobe University and the boundary conditions are based on actual sound absorber installed in the offices. The installed absorber is a porous type absorber, which is different from the previous example. Additionally, as a further demonstration of the effectiveness of PUFEM, we present computed SPL distributions inside rooms with a fine spatial resolution, comparing with the reference solution and the standard FEM. Figure 8 presents a coupled room $\left(S_{\mathrm{a}}=60.48 \mathrm{~m}^{2}\right)$ composed of four rooms where the largest room is the same as that used in the first numerical example and where the other three are soundproof rooms with highly absorbing boundaries. The room boundaries comprise reflecting impedance boundary $\Gamma_{z, 1}$ and highly absorbing impedance boundary $\Gamma_{z, p}$ of a rigid-backed porous sound absorber. We gave a real valued surface impedance corresponding to $\alpha_{0}=0.05$ to the reflecting boundary $\Gamma_{z, 1}$. An equivalent fluid model [51] with Miki's empirical equation [52] was used to calculate the surface impedance of the porous absorber. Regarding the porous material, glass wool of $32 \mathrm{~kg} / \mathrm{m}^{3}$ with $100 \mathrm{~mm}$ thickness was assumed. The flow resistivity was set as 13,900 Pa s/m². The absorption characteristics of $z_{\mathrm{n}}$ and $\alpha_{0}$ are presented in Figure 8 . The sound absorber has high absorption coefficient greater than 0.9 at frequencies higher than $500 \mathrm{~Hz}$. Therefore, in this problem, sound fields have high SPL difference among the largest sized room and the three soundproof rooms. We applied $v=1 \mathrm{~m} / \mathrm{s}$ for the vibration boundary $\Gamma_{\mathrm{v}}$. We placed 18 sound receivers in the room.
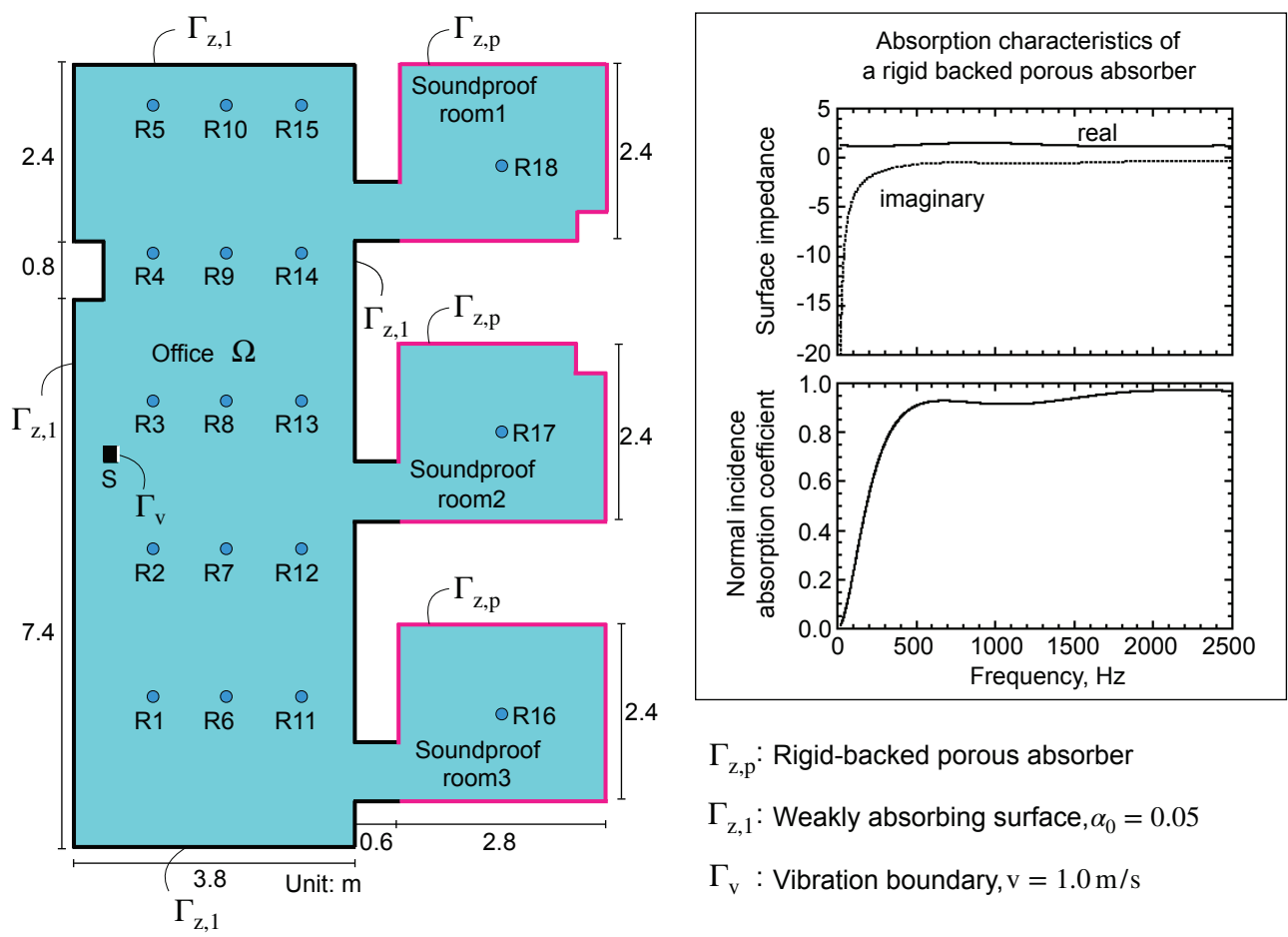

$\Gamma_{\mathrm{z}, \mathrm{p}}:$ Rigid-backed porous absorber

$\Gamma_{\mathrm{z}, 1}:$ Weakly absorbing surface, $\alpha_{0}=0.05$

$\Gamma_{\mathrm{v}}:$ Vibration boundary, $\mathrm{v}=1.0 \mathrm{~m} / \mathrm{s}$

Figure 8. Coupled room model including a vibration boundary, with impedance boundaries of a reflecting surface and a rigid-backed porous absorber: $S, R$ respectively represent the sound source and receivers.

Figure 9 shows a PUFEM mesh discretized using rectangular elements of various lengths in the range of $0.2-0.4 \mathrm{~m}$. The mesh includes three times larger elements than wavelength at the upper-limit frequency. The constant $C$ for plane wave enrichment varies from 5 to 14 with an interval of one. In addition, $N_{\text {ele }}$ and $N_{\text {node }}$ respectively denote 413 and 493 . However, similarly to the earlier numerical example, we used two FE meshes respectively discretized with $0.01 \mathrm{~m}$ square elements and $0.005 \mathrm{~m}$ 
square elements to calculate the reference solutions. The $0.01 \mathrm{~m}$ mesh was used to calculate frequency responses at $20 \mathrm{~Hz}$ to $1500 \mathrm{~Hz}$. For higher frequencies, we used $0.005 \mathrm{~m}$ mesh. The DOF of the meshes are, respectively, 612,000 and 2,448,000.

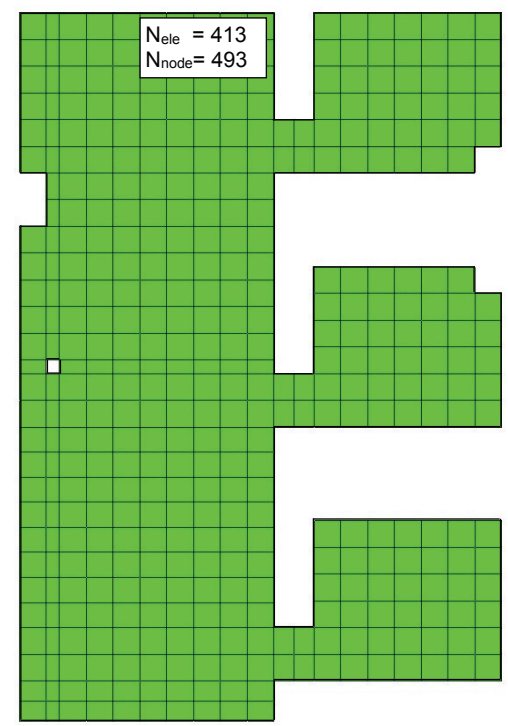

Figure 9. PUFEM mesh for coupled room analysis: The $n_{w}$ range is the same as Mesh 2 in Figure 3.

\subsubsection{Results and Discussion}

Figure 10 presents a comparison of RMS errors among results with different values of $C$. The figure also includes standard FEM results obtained using $0.01 \mathrm{~m}$ mesh having 612,000 DOF. The RMS error of PUFEM is reduced at higher frequencies with larger values of $C$. The PUFEM with $C \geq 6$ were more accurate than the standard FEM results at above $500 \mathrm{~Hz}$ band. At the highest $2 \mathrm{kHz}$ band, PUFEM using $C=13$ shows a smaller RMS value of $1.4 \mathrm{~dB}$ than the $7.5 \mathrm{~dB}$ in the standard FEM. The magnitude is $1 / 5.4$ of the standard FEM. Here, the change in DOF of PUFEM is the same as that shown in Figure 5; in addition, the DOFs change from 3451 to 26,129 at $20 \mathrm{~Hz}$ to $2.5 \mathrm{kHz}$. The results demonstrate clearly that the PUFEM can also perform well for more complex coupled fields with a small amount of DOF.

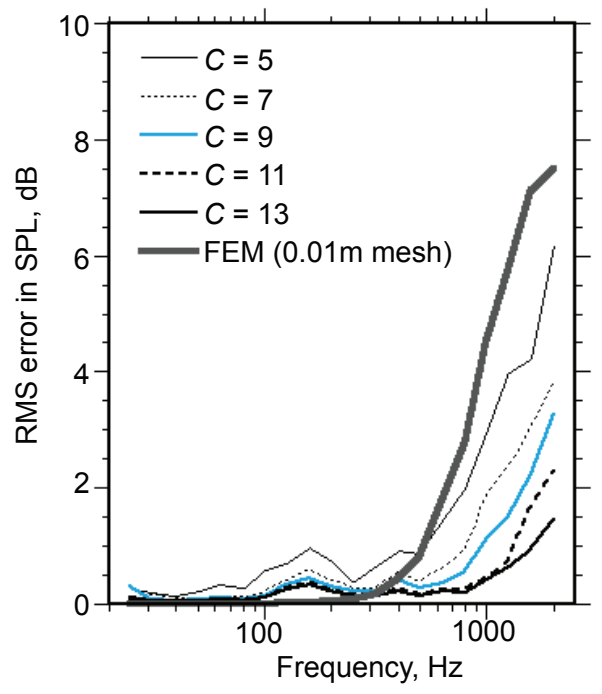

Figure 10. Comparison of RMS errors among results with different values of $C$ : The standard FEM results obtained using $0.01 \mathrm{~m}$ mesh are also shown. 
Furthermore, Figure 11 depicts SPL distributions at $2 \mathrm{kHz}$ and $2.5 \mathrm{kHz}$ among Ref, PUFEM, and standard FEM, where Ref and the standard FEM used $0.005 \mathrm{~m}$ mesh having 2,448,000 DOF. The PUFEM used $C=12$ at $2 \mathrm{kHz}$ and $C=13$ at $2.5 \mathrm{kHz}$. The DOFs are, respectively, 21,692 and 26,129. In addition, PUFEM results were shown at the same 2,448,000 nodal points as in Ref and standard FEM. RMS error $L_{\text {rms }}$ was calculated with all nodal points. The $L_{\text {rms }}$ values for PUFEM and standard FEM are also included in Figure 11. The SPL distributions at $2 \mathrm{kHz}$ and $2.5 \mathrm{kHz}$ of PUFEM agree very well with those of Ref, exhibiting smaller values of $L_{\mathrm{rms}}$ than the standard FEM results. For PUFEM results, the value is $1.3 \mathrm{~dB}$ at $2 \mathrm{kHz}$ and $1.5 \mathrm{~dB}$ at $2.5 \mathrm{kHz}$. The standard FEM shows large errors of $5.6 \mathrm{~dB}$ at $2 \mathrm{kHz}$ and $7.1 \mathrm{~dB}$ at $2.5 \mathrm{kHz}$. We can observe in the standard FEM results by which SPL distributions differ from those of Ref in both frequencies. For example, at $2.5 \mathrm{kHz}$, SPL values in the four rooms show lower values than Ref. Clearer dips in SPL distributions are apparent in the three soundproof rooms. These results suggest that the DOF reduction in PUFEM reaches at least 1/100 of the standard FEM even for large problems including practical boundary conditions.
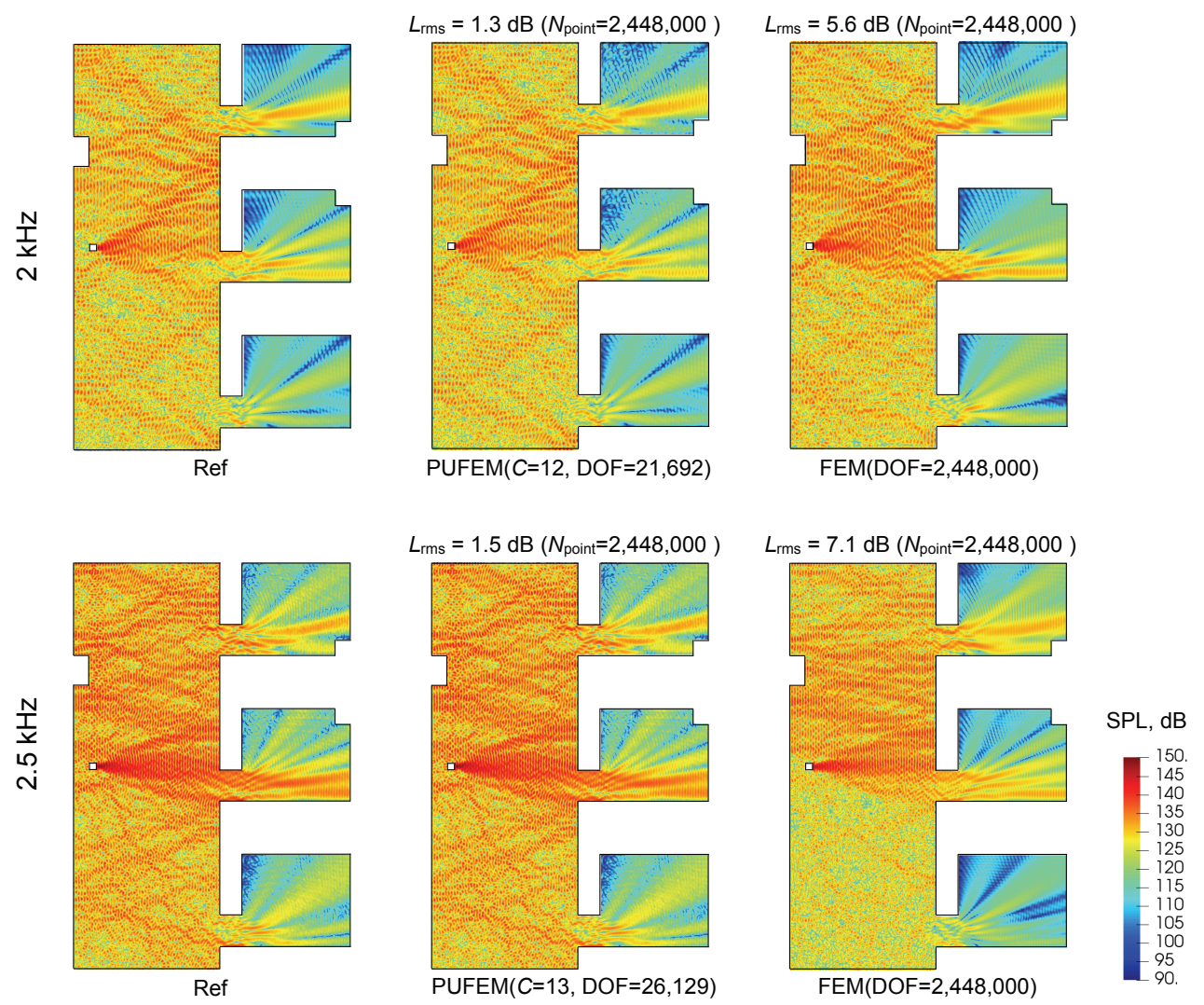

Figure 11. SPL distributions at $2 \mathrm{kHz}$ (upper) and $2.5 \mathrm{kHz}$ (lower) among Ref (left), PUFEM (center), and standard FEM (right).

However, we must state an important aspect in the use of PUFEM at this stage. In Figure 11, we present results of PUFEM with $C=12$ instead of $C=13$ at $2 \mathrm{kHz}$ because the result with $C=13$ showed noisy SPL distributions, as shown in Figure 12. In the present figure, it is apparent that the solution did not converge to the reference solution in the three soundproof rooms because of the ill-conditioning of the linear system, as described previously. From this result, it can be inferred that there exists a proper number of plane waves for enrichment to obtain reliable results. Finally, in Figure 13, we present comparisons of SPL distributions between Ref and PUFEM with C=13 at three lower frequencies of $125 \mathrm{~Hz}, 250 \mathrm{~Hz}$, and $500 \mathrm{~Hz}$, where modal behavior is enhanced because of low diffuseness. The figure also includes RMS error values calculated at 615,020 nodal points. The agreement of SPL distributions between PUFEM and Ref is excellent with RMS errors less than 
$0.25 \mathrm{~dB}$ at all frequencies. The PUFEM results used $C=13$, but lower values of $C$ can be used at the low frequencies shown in Figure 10.

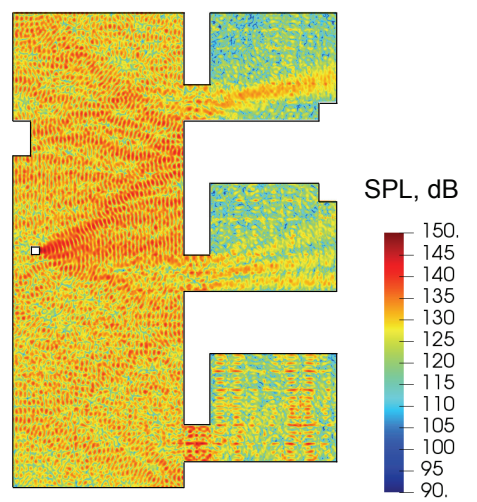

Figure 12. SPL distributions at $2 \mathrm{kHz}$ calculated using PUFEM with $C=13$.
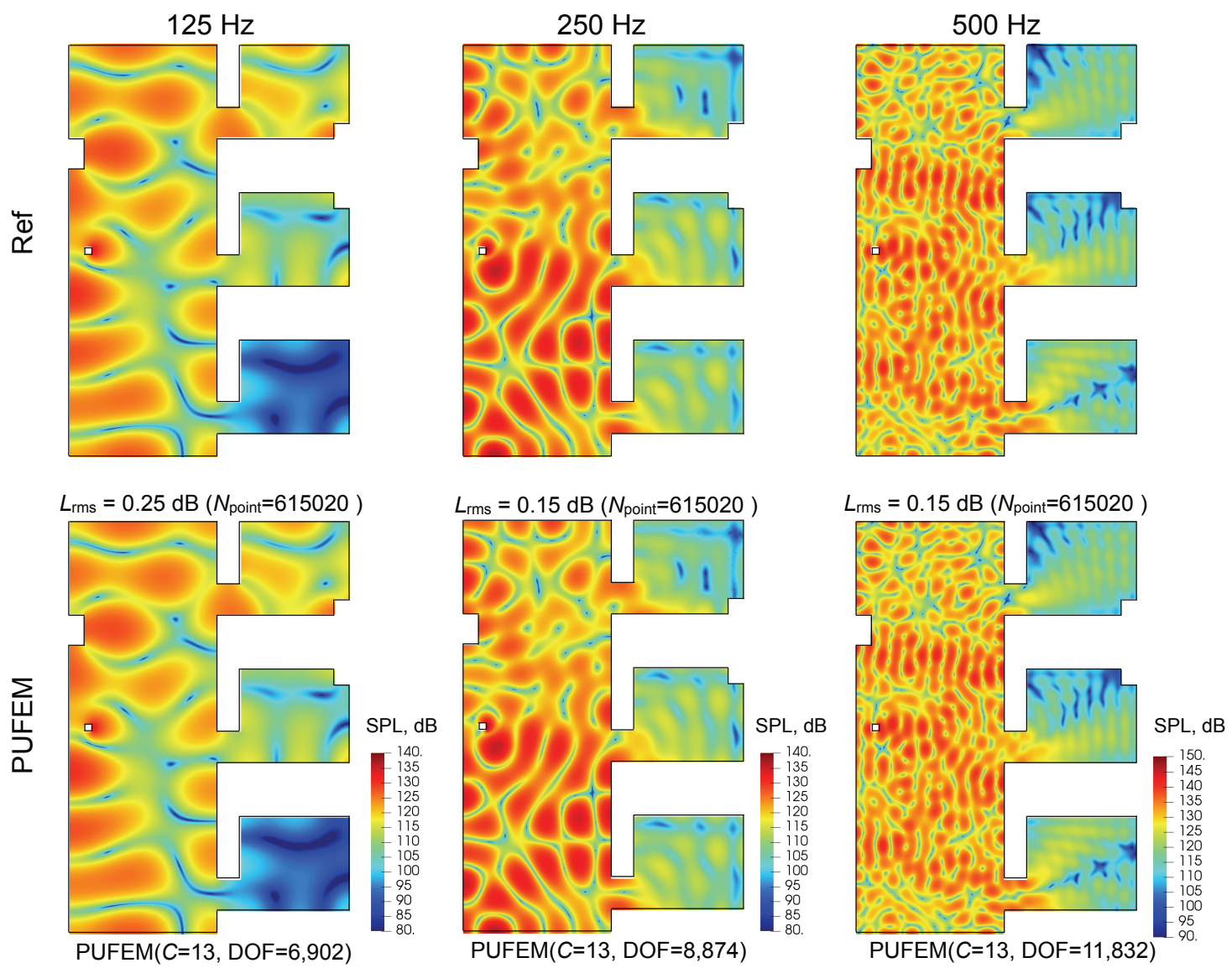

Figure 13. Comparisons of SPL distributions between Ref (upper) and PUFEM (lower) at $125 \mathrm{~Hz}$ (left), $250 \mathrm{~Hz}$ (center) and $500 \mathrm{~Hz}$ (right).

\section{Conclusions}

This report described a study of a room acoustics solver based on plane-wave-enriched FEM using low-order quadrilateral elements and local-reaction impedance boundaries. We discussed the potential of plane-wave-enriched FEM as a room acoustic solver to solve the issues on wave-based room acoustic simulations via performance examination on $2 \mathrm{D}$ real-scale room acoustic problems with realistic boundary conditions in comparison with the standard second-order accurate FEM. In particular, we examined its accuracy for multi-frequency analysis including fine frequency resolution 
quantitatively by comparison with reference solutions calculated using a fourth-order accurate FEM. The tested frequency range is $20 \mathrm{~Hz}$ to $2.5 \mathrm{kHz}$ with $1 \mathrm{~Hz}$ interval. We used two numerical room models of a single room and a coupled room, each with 13-20 times larger interior sound fields than those used in earlier studies, and also including frequency-dependent impedance boundary conditions of sound absorbers commonly used in room acoustic simulations i.e., Helmholtz resonators and porous absorbers. The numerical results clearly revealed advantages of using plane wave enriched finite elements against the standard finite elements in terms of the resulting accuracy, required DOF to obtain the same accurate results, and also the ease of mesh generation. More specifically, the two numerical examples demonstrated that PUFEM can predict a broadband frequency response at low to high frequencies accurately using a single coarse mesh with much less DOF than the standard FEM. The reduction in DOF reaches at least $1 / 100$ of the standard FEM. In the single-room problem, PUFEM produced acceptably accurate results at all frequencies with only 16,271 degrees of freedom, whereas the standard FEM showed unacceptable results because of the inherent larger dispersion error property despite the use of mesh with 1,599,840 DOF. Similarly, in the coupled room problem, the PUFEM results obtained using coarse mesh with 26,129 DOF showed much lower error values than those with 2,448,000 DOF of the standard FEM. Results demonstrate that PUFEM using plane wave enrichment has noteworthy potential for increasing the applicability of wave-based room acoustic simulations. However, numerical results also indicate that an appropriate number of plane waves exists for enrichment. When inappropriate numbers of plane waves are added to nodal points, the PUFEM produces unstable results because of the resulting ill-conditioned linear systems. Therefore, we expect to develop the mode of adding plane waves properly in future studies so that multi-frequency analysis can perform efficiently and robustly. Furthermore, we showed the mesh size effect on PUFEM results in limited conditions. Therefore, our future works will include showing the effect in detail. Application of PUFEM solver to 3D room acoustic simulations will be presented in future reports.

Author Contributions: Conceptualization, T.O.; Investigation, T.O.; Methodology, T.O. and M.S.M.; Project administration, K.S.; Validation, T.O.; Visualization, T.O.; Writing-original draft, T.O.; Writing-review and editing, T.O., M.S.M., and K.S. All authors have read and agreed to the published version of the manuscript.

Funding: This work was supported by JSPS KAKENHI Grant No. 17K14771. The second author is partially supported by JSPS Invitational Fellowship No. L19554.

Conflicts of Interest: The authors declare that they have no conflict of interest related to this report or the study it describes.

\section{References}

1. Easwaran, V.; Craggs, A. On further validation and use of the finite element method to room acoustics. J. Sound Vib. 1995, 187, 195-212. [CrossRef]

2. Easwaran, V.; Craggs, A. Transient response of lightly damped rooms: A finite element approach. J. Acoust. Soc. Am. 1996, 99, 108-113. [CrossRef]

3. Otsuru, T.; Tomiku, R.; Toyomasu, M.; Takahashi, Y. Finite element sound field analysis of rooms in built environment. In Proceedings of the Eighth International Congress on Acoustics, Hong Kong, China, 2-6 July 2001.

4. Otsuru, T.; Okamoto, N.; Okuzono, T.; Sueyoshi, T. Applications of large-scale finite element sound field analysis onto room acoustics. In Proceedings of the 19th International Congress on Acoustics, Madrid, Spain, 2-7 September 2007.

5. Okamoto, N.; Tomiku, R.; Otsuru, T.; Yasuda, Y. Numerical analysis of large-scale sound fields using iterative methods part II: Application of Krylov subspace methods to finite element analysis. J. Comput. Acoust. 2007, 15, 473-493. [CrossRef]

6. Yasuda, Y.; Sakamoto, S.; Kosaka, Y.; Sakuma, T.; Okamoto, N.; Oshima, T. Numerical analysis of large-scale sound fields using iterative methods part I: Application of Krylov subspace methods to boundary element analysis. J. Comput. Acoust. 2007, 15, 449-471. [CrossRef]

7. Botteldooren, D. Finite-difference time-domain simulation of low-frequency room acoustic problems. J. Acoust. Soc. Am. 1995, 98, 3302-3308. [CrossRef] 
8. LoVetri, J.; Mardare, D.; Soulodre, G. Modeling of the seat dip effect using the finite-difference time-domain method. J. Acoust. Soc. Am. 1996, 100, 2204-2212. [CrossRef]

9. Sakamoto, S.; Nagatomo, H.; Ushiyama, A.; Tachibana, H. Calculation of impulse responses and acoustic parameters in a hall by the finite-difference time-domain method. Acoust. Sci. Technol. 2008, 29, 256-265. [CrossRef]

10. Kowalczyk, K.; Walstijn, M. Formulation of locally reacting surfaces in FDTD/K-DWM modelling of acoustic spaces. Acta Acust. United Acta 2008, 94, 891-906. [CrossRef]

11. Okuzono, T.; Otusru, T.; Tomiku, R.; Okamoto, N. Fundamental accuracy of time domain finite element method for sound-field analysis of rooms. Appl. Acoust. 2010, 71, 940-946. [CrossRef]

12. Mehra, R.; Raghuvanshi, N.; Savioja, L.; Lin, M.C.; Manocha, D. An efficient GPU-based time domain solver for the acoustic wave equation. Appl. Acoust. 2012, 73, 83-94. [CrossRef]

13. Simonaho, S.P.; Lähivaara, T.; Huttunen, T. Modeling of acoustic wave propagation in time-domain using the discontinuous Galerkin method-A comparison with measurements. Appl. Acoust. 2012, 73, 173-183. [CrossRef]

14. Okuzono, T.; Otsuru, T.; Tomiku, R.; Okamoto, N. A finite element method using dispersion reduced spline elements for room acoustics simulation. Appl. Acoust. 2014, 79, 1-8. [CrossRef]

15. Hornikx, M.; Krijnen, T.; Harten, L. The open source pseudospectral time-domain method for acoustic propagation. Comput. Phys. Commun. 2016, 203, 298-308. [CrossRef]

16. Okuzono, T.; Sakagami, K. A frequency domain finite element solver for acoustic simulations of 3D rooms with microperforated panel absorbers. Appl. Acoust. 2018, 129, 1-12. [CrossRef]

17. Yoshida, T.; Okuzono, T.; Sakagami, K. Numerically stable explicit time-domain finite element method for room acoustics simulation using an equivalent impedance model. Noise Control Eng. J. 2018, 66, 176-188. [CrossRef]

18. Okuzono, T.; Shimizu, N.; Sakagami, K. Predicting absorption characteristics of single-leaf permeable membrane absorbers using finite element method in a time domain. Appl. Acoust. 2019, 151, 172-182. [CrossRef]

19. Rabisse, K.; Ducourneau, J.; Faiz, A.; Trompette, N. Numerical modelling of sound propagation in rooms bounded by walls with rectangular irregularities and frequency-dependent impedance. J. Sound Vib. 2019, 440, 291-314. [CrossRef]

20. Wang, H.; Sihar, I.; Pagán Muñoz, R.; Hornikx, M. Room acoustics modelling in the time-domain with the nodal discontinuous Galerkin method. J. Acoust. Soc. Am. 2019, 145, 2650-2663. [CrossRef]

21. Pind, F.; Engsig-Karup, A.; Jeong, C.H.; Hesthaven, J.S.; Mejling, M.S; Strømann-Andersen, J. Time domain room acoustic simulations using the spectral element method. J. Acoust. Soc. Am. 2019, 145, 3299-3310. [CrossRef]

22. Toyoda, M.; Eto, D. Prediction of microperforated panel absorbers using the finite-difference time-domain method. Wave Motion 2019, 86, 110-124. [CrossRef]

23. Yasuda, Y.; Saito, K.; Sekine, H. Effects of the convergence tolerance of iterative methods used in the boundary element method on the calculation results of sound fields in rooms. Appl. Acoust. 2020, 157, 106997. [CrossRef]

24. Hoshi, K.; Hanyu, T.; Okuzono, T.; Sakagami, K.; Yairi, M.; Harada, S.; Takahashi, S.; Ueda, Y. Implementation experiment of a honeycomb-backed MPP sound absorber in a meeting room. Appl. Acoust. 2020, 157, 107000. [CrossRef]

25. Yasuda, Y.; Ueno, S.; Kadota, M.; Sekine, H. Applicability of locally reacting boundary conditions to porous material layer backed by rigid wall: Wave-based numerical study in non-diffuse sound field with unevenly distributed sound absorbing surfaces. Appl. Acoust. 2016, 113, 45-57. [CrossRef]

26. Otsuru, T.; Tomiku, R. Basic characteristics and accuracy of acoustic element using spline function in finite element sound field analysis. Acoust. Sci. Technol. 2000, 21, 87-95. [CrossRef]

27. Okuzono, T.; Sakagami, K.; Otsuru, T. Dispersion-reduced time domain FEM for room acoustics simulation. In Proceedings of the 23rd International Congress on Acoustics, Aachen, Germany, 9-13 September 2019.

28. Okuzono, T.; Otsuru, T.; Tomiku, R.; Okamoto, N. Application of modified integration rule to time-domain finite-element acoustic simulation of rooms. J. Acoust. Soc. Am. 2012, 132, 804-813. [CrossRef] [PubMed]

29. Melenk, J.M.; Babuška, I. Partition of unity finite element method: Basic theory and applications. Comput. Methods Appl. Mech. Eng. 1996, 139, 289-314. [CrossRef]

30. Laghrouche, O.; Bettess, P.; Astley, J. Modelling of short wave diffraction problems using approximating systems of plane waves. Int. J. Numer. Meth. Eng. 2002, 54, 1501-1533. [CrossRef]

31. Laghrouche, O.; Bettess, P.; Perrey-Debain, E.; Trevelyan, J. Wave interpolation finite elements for Helmholtz problems with jumps in the wave speed. Comput. Methods Appl. Mech. Eng. 2005, 194, 367-381. [CrossRef] 
32. Laghrouche, O.; Mohamed, M.S. Locally enriched finite elements for the Helmholtz equation in two dimensions. Comput. Struct. 2010, 88, 1469-1473. [CrossRef]

33. Mohamed, M.S.; Laghrouche, O. Some numerical aspects of the PUFEM for efficient solution of 2D Helmholtz problems. Comput. Struct. 2010, 88, 1484-1491. [CrossRef]

34. Mohamed, M.S. Numerical Aspects of the PUFEM for Efficient Solution of Helmholtz Problems. Ph.D. Thesis, Heriot-Watt University, Edinburgh, UK, 2010.

35. Diwan, G.C.; Mohamed, M.S. Pollution studies for high order isogeometric analysis and finite element for acoustic problems. Comput. Methods Appl. Mech. Eng. 2019, 350, 701-718. [CrossRef]

36. Chazot, J.D.; Nennig, B.; Perrey-Debain, E. Performances of the Partition of Unity Finite Element Method for the analysis of two-dimensional interior sound fields with absorbing materials. J. Sound Vib. 2013, 332, 1918-1929. [CrossRef]

37. Chazot, J.D.; Perrey-Debain, E. The partition of unity finite element method for the simulation of waves in air and poroelastic media. J. Acoust. Soc. Am. 2014, 135, 724-733. [CrossRef] [PubMed]

38. Christodoulou, K.; Laghrouche, O.; Mohamed, M.S.; Trevelyan, J. High-order finite elements for the solution of Helmholtz problems. Comput. Struct. 2017, 191, 129-139. [CrossRef]

39. Banerjee, S.; Sukumar, N. Exact integration scheme for planewave-enriched partition of unity finite element method to solve the Helmholtz problem. Comput. Methods Appl. Mech. Eng. 2017, 317, 619-648. [CrossRef]

40. Dinachandra, M.; Raju, S. Plane wave enriched Partition of Unity Isogeometric Analysis (PUIGA) for 2D-Helmholtz problems. Comput. Methods Appl. Mech. Eng. 2018, 335, 380-402. [CrossRef]

41. Craggs, A. A finite element model for rigid porous absorbing materials. J. Sound Vib. 1978, 61, 101-111. [CrossRef]

42. Craggs, A. Coupling of finite element acoustic absorption models. J. Sound Vib. 1979, 66, 605-613. [CrossRef]

43. Easwaran, V.; Munjal, M.L. Finite element analysis of wedges used in anechoic chambers. J. Sound Vib. 1993, 160, 333-350. [CrossRef]

44. Allard, J.F.; Atalla, N. Sound propagation in porous materials having a rigid frame. In Propagation of Sound in Porous Media: Modeling Sound Absorbing Materials, 2nd ed.; John Wiley \& Sons, Ltd.: Chichester, UK, 2009; pp. 73-109.

45. Allard, J.F.; Atalla, N. Finite element modeling of poroelastic materials. In Propagation of Sound in Porous Media: Modeling Sound Absorbing Materials, 2nd ed.; John Wiley \& Sons, Ltd.: Chichester, UK, 2009; pp. 309-349.

46. Hiptmair, R.; Moiola, A.; Perugia, I. Survey of Trefftz methods for the Helmholtz equation. In Building Bridges: Connections and Challenges in Modern Approaches to Numerical Partial Differential Equations; Springer: Cham, Switzerland, 2016; pp. 237-278.

47. Guddati, M.N.; Yue, B. Modified integration rules for reducing dispersion error in finite element methods. Comput. Methods Appl. Mech. Eng. 2004, 193, 275-287. [CrossRef]

48. Otsuru, T.; Okuzono, T.; Tomiku, R.; Asniawaty, K.; Okamoto, N. Large-scale finite element sound field analysis of rooms using a practical boundary modeling technique. In Proceedings of the 19th International Congress on Sound and Vibration, Vilnius, Lithuania, 8-12 July 2012.

49. Okuzono, T.; Sakagami, K. A finite-element formulation for room acoustics simulation with microperforated panel sound absorbing structures: Verification with electro-acoustical equivalent circuit theory and wave theory. Appl. Acoust. 2015, 95, 20-26. [CrossRef]

50. Sakagami, K.; Morimoto, M.; Yairi, M. A note on the effect of vibration of a microperforated panel on its sound absorption characteristics. Acoust. Sci. Technol. 2005, 26, 204-207. [CrossRef]

51. Allard, J.F.; Atalla, N. Acoustic impedance at normal incidence of fluids. Substitution of a fluid layer for a porous layer. In Propagation of Sound in Porous Media: Modeling Sound Absorbing Materials, 2nd ed.; John Wiley \& Sons, Ltd.: Chichester, UK, 2009; pp. 15-27.

52. Miki, Y. Acoustical properties of porous materials-Modifications of Delany-Bazley models. J. Acoust. Soc. Jpn. 1990, 11, 19-24. [CrossRef]

(C) 2020 by the authors. Licensee MDPI, Basel, Switzerland. This article is an open access article distributed under the terms and conditions of the Creative Commons Attribution (CC BY) license (http://creativecommons.org/licenses/by/4.0/). 